\title{
Circulating levels of periostin may help identify patients with more aggressive colorectal cancer
}

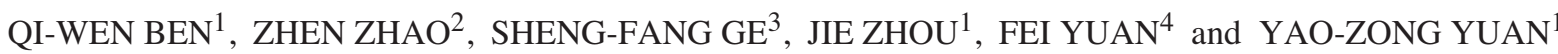 \\ Departments of ${ }^{1}$ Gastroenterology, ${ }^{2}$ Laboratory Medicine, Ruijin Hospital, Shanghai Jiaotong University \\ School of Medicine; ${ }^{3}$ Department of Biochemistry and Molecular Biology, Basic Medical College, \\ Shanghai Jiaotong University; ${ }^{4}$ Department of Pathology, Ruijin Hospital, Shanghai Jiaotong \\ University School of Medicine, Shanghai, P.R. China
}

Received October 1, 2008; Accepted November 29, 2008

DOI: 10.3892/ijo_00000208

\begin{abstract}
Elevated levels of periostin have been implicated as playing important roles in tumor invasion and metastasis in various tissues. Thus, we determined whether serum periostin levels were associated with progression and poor prognosis in colorectal cancer (CRC) patients. We measured serum periostin levels by ELISA in 67 CRC patients and 120 controls. We also evaluated periostin expression in human CRC specimens $(n=15)$ using immunohistochemistry, and measured expression of periostin mRNA in $7 \mathrm{CRC}$ tissue samples, matched normal tissues and in 4 colon cancer cell lines by RT-PCR. We analyzed the relationship between serum levels of periostin and other clinicopathologic characteristics in patients with CRC. The serum levels of periostin in CRC patients $(40.9 \pm 15.4 \mathrm{ng} / \mathrm{ml})$ were significantly elevated compared to that in healthy volunteers $(21.0 \pm 7.3 \mathrm{ng} / \mathrm{ml}$, $\mathrm{P}<0.0001)$ and benign colorectal polyps or adenomas $(22.4 \pm 8.5 \mathrm{ng} / \mathrm{ml}, \mathrm{P}<0.0001)$. Higher preoperative serum levels of periostin in CRC were found to correlate with distant metastasis $(\mathrm{P}=0.003)$, advanced-stage disease (stage III/IV, $\mathrm{P}<0.0001)$ and poor prognosis. Preoperative serum periostin levels of 15 cases were significantly higher than matched postoperative levels $(47.2 \pm 13.5 \mathrm{ng} / \mathrm{ml}$ vs. $31.3 \pm 11.0 \mathrm{ng} / \mathrm{ml}$, $\mathrm{P}=0.008)$. Twelve of 15 patients $(80 \%)$ had positive immunohistochemical periostin staining in CRC samples. Interestingly, periostin mRNA was highly upregulated in CRCs in comparison with matched normal tissues, and no expression of periostin mRNA was detected in 4 colon cancer cell lines. Serum levels of periostin detected by ELISA may be of clinical value in identifying patients who may be at high risk for aggression and metastasis of CRC. Periostin may be
\end{abstract}

Correspondence to: Dr Yao-Zong Yuan, Department of Gastroenterology, Ruijin Hospital, Shanghai Jiaotong University School of Medicine, Shanghai, P.R. China

E-mail: yyz28@medmail.com.cn

Key words: colorectal cancer, periostin, immunohistochemistry, RT-PCR, ELISA, prognosis produced by the stromal cells surrounding the tumor, but not by the CRC cells themselves.

\section{Introduction}

Colorectal cancer (CRC) is the second most common cancer in developed countries, and $\sim 1$ million new cases worldwide every year (1). Despite advances in molecular biology of the pathogenesis of cancer and in its management, a variety of cancer patients, including CRC patients, would eventually die from recurrence and dissemination of cancer soon after surgery. Therefore, identifying novel biological markers related to tumor aggressiveness and metastasis is urgently needed.

Approximately $30 \%$ of patients with localized CRC have micrometastatic disease that is difficult to detect at the time of diagnosis and treatment and results in disease recurrence and death several years after diagnosis (2). Serum biomarkers would be valuable in facilitating non-invasive diagnosis of early-stage malignant tumor; they would also be useful to clinicians in detecting micrometastasis, determining the risk of recurrence, and predicting prognosis, thus helping clinicians determine suitable therapy.

It is reported that cell adhesion molecules (CAMs) do not only play important roles in keeping cells close contact, but are also involved in pathologic conditions, including tumor progression, invasion, and metastasis $(3,4)$. Periostin, secreted by osteoblasts, shares a structural homology to insect fasciclin I and supports adhesion of osteoblasts $(5,6)$, leading to a hypothesis that it functions to modulate cell-to-matrix interactions and acts in cell adhesion, migration, and growth. Periostin can serve as a ligand for several integrins, such as $\alpha v ß 3$, $\alpha v ß 5(7,8)$ or $\alpha 6 \beta 4(9)$, and activate the Akt/PKB signaling pathway through $\alpha \mathrm{v} B 3$ integrins to increase colon cancer cell survival (7). Whereas integrin expression level is supposed to be related to metastasis, relapse and prognosis of CRC $(10,11)$. In addition, expression of periostin is reported to be elevated in certain malignant tumors including head and neck cancer $(12,13)$, nasopharyngeal carcinoma (14), breast cancer (15-17), CRC (7), and pancreatic carcinoma $(9,18)$. Circulating levels of periostin was found to be elevated in thymoma, breast cancer with bone metastases, and pancreatic carcinoma $(9,19-21)$. However, to our 
knowledge, there have been no studies on circulating levels of periostin in human CRC. We hypothesize that measuring serum levels of periostin may provide informative markers for monitoring CRC before surgery.

In the present study, we focused on serum levels of periostin in patients with CRC, colorectal polyps or adenomas and healthy volunteers using ELISA. Thereafter, we examined the clinical implications of circulating periostin by investigating the relationship between serum periostin levels and clinicopathologic characteristics of CRC patients. We also measured the expression of periostin mRNA and protein in CRC specimens and cell lines by RT-PCR and immunohistochemistry analysis to determine the site of periostin production.

\section{Materials and methods}

Subject and follow-up. The study group consisted of 67 untreated patients with CRC, hospitalized in the department of surgery, Rui-jin Hospital between 10/2006 and 6/2007. CRC was diagnosed in surgically resected tissues or biopsy tissues. These patients were 42 males and 25 females from 28 to 84 years of age $(62 \pm 12$, mean \pm SD). Fifty-six percent and $44 \%$ of the subjects were affected, respectively, by carcinomas of rectum and colon. Fifty-five percent of CRC patients were staged as early disease (stage I and II) according to TNM staging system; and $45 \%$ as advanced disease (stage III and IV) (22). Sixty-three healthy volunteers and 57 patients with benign colorectal polyps or adenomas were recruited as controls. Demographic information of all subjects is reported in Table I. Patients who were unable or unwilling to give informed consent or who had undergone chemotherapy or radiation therapy before surgery were excluded, as were patients and controls with rheumatic disease, acute infection, HIV or other types of cancer. A 10-ml blood sample was drawn from each subject prior to surgery, spun, aliquot, and stored at $-80^{\circ} \mathrm{C}$ until testing. Additionally 15 blood samples were collected from CRC patients one month after surgery. Classical tumor markers of CEA were routinely detected by chemiluminescence immunoassay (CLIA, Abbott Architect i2000) at the clinical ward before operation. Follow-up was performed for the whole group until the end of June 1, 2008. Overall survival time was calculated as the time in months from the date of diagnosis to death (for non-censored events) or to the most recent contact/visit (for censored events) as of June 1, 2008. All investigations described in this study were done after informed consent and in accordance with the Institutional Review Board and the Ethics Committee of Ruijin Hospital (Shanghai, P.R. China).

Tissue sample. For RNA extraction, 7 representative fragments of fresh tumor and matched normal tissues at least $5 \mathrm{~cm}$ away from malignant tissues were taken within $1 \mathrm{~h}$ after surgery. They were immediately snap-frozen in liquid nitrogen, and then stored at $-80^{\circ} \mathrm{C}$ until processing. Informed consent was obtained from all patients before surgery.

Cell culture. SW480, LS174T, SW620 and HT-29 cells, derived from human colon adenocarcinoma, were obtained from the American Type Culture Collection (ATCC, Manassas, VA). Cells were grown in RMPI-1640 medium (Invitrogen,
Table I. Patient demographics.

\begin{tabular}{lcccc}
\hline & & & \multicolumn{2}{c}{ Age } \\
\cline { 4 - 5 } Class & No. & Gender & Mean (SD) & Range \\
\hline CRC & 42 & M & $61(14)$ & $28-82$ \\
& 25 & F & $62(11)$ & $40-84$ \\
Colorectal polyps & 33 & M & $58(11)$ & $29-76$ \\
or adenoma & 24 & F & $56(13)$ & $33-78$ \\
Healthy volunteers & 34 & M & $55(9)$ & $24-69$ \\
& 29 & F & $53(10)$ & $22-72$ \\
All & 187 & M/F & $57(12)$ & $22-84$ \\
\hline
\end{tabular}

Carlsbad, CA) supplemented with $10 \%$ heat-inactivated fetal bovine serum and $100 \mathrm{U} / \mathrm{ml}$ of penicillin-streptomycin (Invitrogen) under the following conditions: $5 \% \mathrm{CO}_{2}$ in air at $37^{\circ} \mathrm{C}$. Media were changed 3 times weekly.

$R T-P C R$. Total RNA was isolated from cultures of cells or human fresh-frozen colorectal tissue samples with the use of TRIzol reagent (Invitrogen) following the manufacturer's protocol. cDNA template was synthesized from $3 \mu \mathrm{g}$ of total RNA using random hexamers and a SuperScript III First-strand synthesis kit (Invitrogen), according to the manufacturer's instructions. PCR was performed on $2 \mu 1$ of $\mathrm{RT}$ products in a $25 \mu 1$ reaction mixture using Ex Taq polymerase (Takara, Ohtsu, Japan). The initial PCR denaturation step was performed for $5 \mathrm{~min}$ at $95^{\circ} \mathrm{C}$, followed by 35 cycles of $40 \mathrm{sec}$ at $95^{\circ} \mathrm{C}$ (melting) and $60 \mathrm{sec}$ at $58^{\circ} \mathrm{C}$ (annealing/ elongation). All reactions were performed in duplicate. The data were normalized to an internal control gene, $\beta$-actin, to control for the amount of RNA in the preparation. Primer sequences were: human periostin, 5'-GGCTTGGCATCT GCTCTG-3' (forward) 5'-TTCTCCCTTGCTTACTCC-3' (reverse, product size: $271 \mathrm{bp}$ ); human 3 -actin, 5'-GGGA CCTGACTGACTACCTCAT-3' (forward) and 5'-CAAG AAAGGGTGTAACGCAACTA-3' (reverse, product size: $617 \mathrm{bp}$ ). The amplification products were electrophoresed on $1.5 \%$ agarose gels.

ELISA. Flat-bottom microplates (96-well) (Becton Dickson, Franklin Lakes, NJ) were coated overnight at $4^{\circ} \mathrm{C}$ with $1 \mu \mathrm{g} / \mathrm{ml}$ $(0.1 \mu \mathrm{g}$ per well) of anti-periostin monoclonal antibody (R\&D Systems, Minneapolis, MN), diluted in $0.05 \mathrm{~mol} / \mathrm{l}$ carbonatebicarbonate. After blocking with a 3\% phosphate-buffered saline-bovine serum albumin solution (PBSA) for $2 \mathrm{~h}$ at room temperature, $100 \mu \mathrm{l} /$ well of undiluted sera, in duplicate, were added. Unbound periostin was removed by washing the plates 5 times with washing buffer and a rabbit polyclonal antibodies to periostin (Ab14041, Abcam, Cambridge, UK) diluted in PBS were added to the plates for $1 \mathrm{~h}$ at room temperature. Horseradish peroxidase-conjugated goat anti-rabbit immunoglobulin (1:500 dilution in PBS) were used for detection. The reaction was terminated by addition of $1 \mathrm{~N}$ sulfuric acid, and the absorbance was measured at $450 \mathrm{~nm}$ with a microtiter plate reader (Titertek Instruments Inc., Huntsville, AL). For 
A

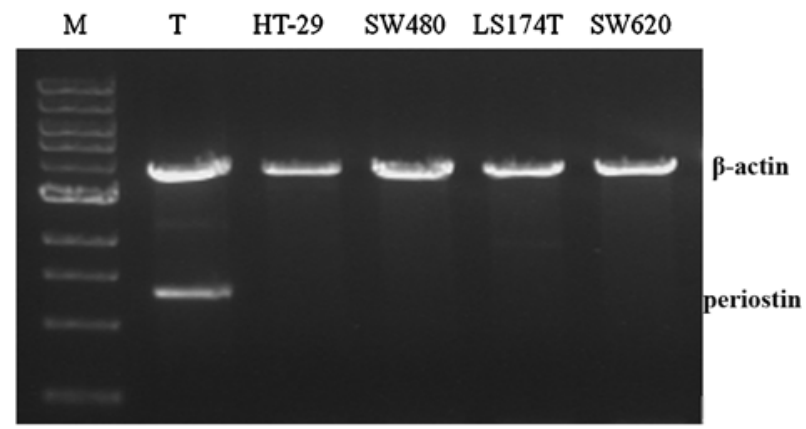

B1

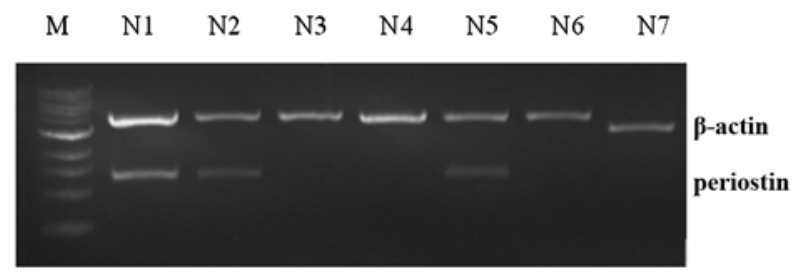

B2

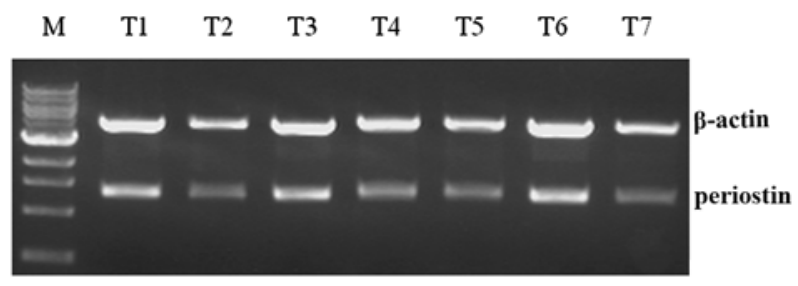

B3

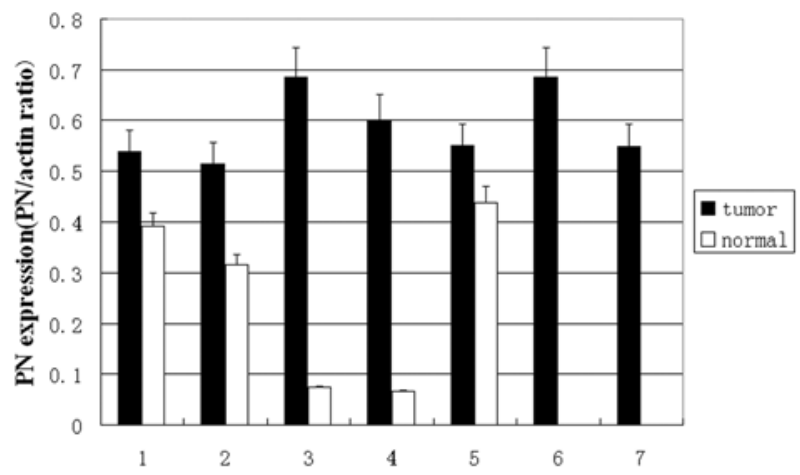

Figure 1. Expression of periostin (PN) mRNA in CRC cell lines, CRC tissue samples and matched normal colonic tissue samples. (A) Expression of periostin mRNA in HT-29, SW620, LS174T and SW480 cells by RT-PCR. $\mathrm{T}$, positive control, CRC tissue sample. (B) Expression of periostin mRNA in matched normal colorectal tissue sample (N1-N7, B1) and colorectal cancer tissue sample (T1-T7, B2). Periostin expression is presented relative to that of $\beta$-actin (B3).

formation of the standard curve to determine serum periostin levels of these patients, diluted recombinant periostin protein (R\&D Systems) at concentrations ranging from $390 \mathrm{pg} /$ well (100 $\mu \mathrm{l})$ to $50 \mathrm{ng} /$ well $(100 \mu \mathrm{l})$, or $100 \mu \mathrm{l} /$ well of $3 \%$ PBSA used as a negative control was added. Serum periostin levels were determined with no knowledge of clinical data.

Immunohistochemistry. Formalin-fixed, paraffin-embedded, archival surgical specimens of CRC were chosen, and a histopathological diagnosis was made on hematoxylin and eosin-stained sections. Specimens were used for immunohistochemistry with a polyclonal (rabbit) anti-human periostin antibody (Ab14041, Abcam). Tissue sections (4 $\mu \mathrm{m})$ were deparaffinized in xylene and rehydrated in graded ethanol. Slides were then immersed in $10 \mathrm{mmol} / \mathrm{l}$ citrate buffer $(\mathrm{pH} 6)$ and microwaved at $750 \mathrm{~W}$ for a total of $10 \mathrm{~min}$. Endogenous peroxidase activity was quenched with $0.6 \%$ hydrogen peroxide. After blocked with $5 \%$ normal goat serum, the samples were incubated with primary antibody for $2 \mathrm{~h}$ at $4^{\circ} \mathrm{C}$, then incubated with peroxidase-labeled (goat) antirabbit antibody (Dako Cytomation, Copenhagen, Denmark). Assessment for the periostin-expressing cells was performed by a pathologist (F.Y.) in a blinded manner. In each experiment, a negative control was included in which primary antibody was replaced by PBS. The negative control sections showed no special immunoreactivity.

Statistical analysis. Data analysis was performed using the SPSS 13.0 statistical software package (SPSS Inc., Chicago, IL). A normal range of periostin concentrations was calculated as the mean in controls $\pm 2 \mathrm{SD}$ (standard deviations). Statistical analysis was done using the Mann-Whitney U test for unpaired samples and the Wilcoxon signed rank test for paired samples. To evaluate the association between serum periostin levels and serum CEA levels, we used nonparametric Spearman's correlation coefficients method. Because of the wide distribution of serum CEA levels, values were plotted on a logarithmic scale. Survival curve was calculated according to the Kaplan-Meier method and P-value was evaluated by the log-rank test for censored survival data. Tests with $\mathrm{P} \leq 0.05$ were considered to be statistically significant and all statistical tests were two-sided.

\section{Results}

$R T-P C R$ analysis of periostin $m R N A$. To determine the expression of periostin mRNA in human CRC cell lines and in human CRC tissues, we performed RT-PCR analysis on four CRC cell lines, 7 CRC tissue samples and matched normal tissues. As shown in Fig. 1, the average of periostin expression levels (periostin/ß-actin signal intensity ratio) was higher in tumors than in matched normal tissues. If significant up-regulation of periostin mRNA exists in primary colorectal cancers, then one would presume that similar levels of expression would be noted in colorectal cancer cell lines. Surprisingly, human periostin mRNA was not present in cell lines (HT29, SW620, LS174T, SW480). This was a representative of two experiments done in triplicate.

Analysis of periostin levels by ELISA. To determine serum periostin levels, we developed a sandwich-ELISA diagnostic kit using a monoclonal antibody to periostin. By adding the recombinant human periostin protein at concentrations ranging from $390 \mathrm{pg} /$ well $(100 \mu \mathrm{l})$ to $50 \mathrm{ng} /$ well $(100 \mu \mathrm{l})$, we 
A

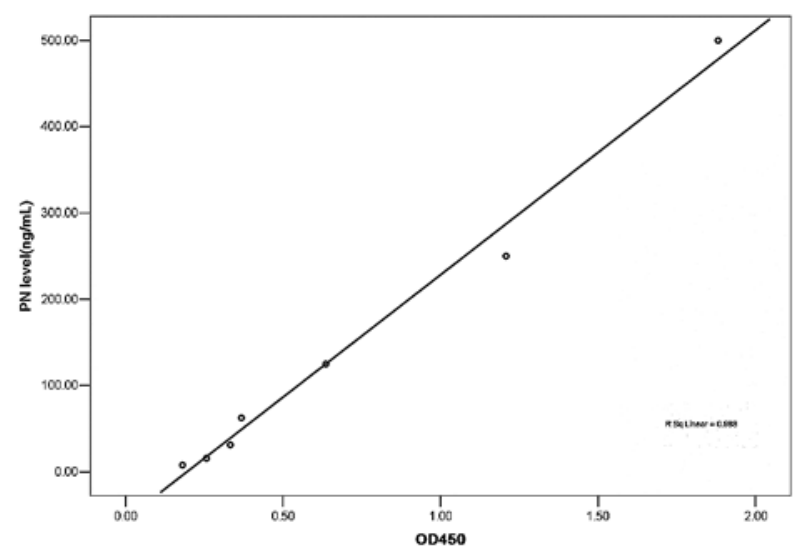

B

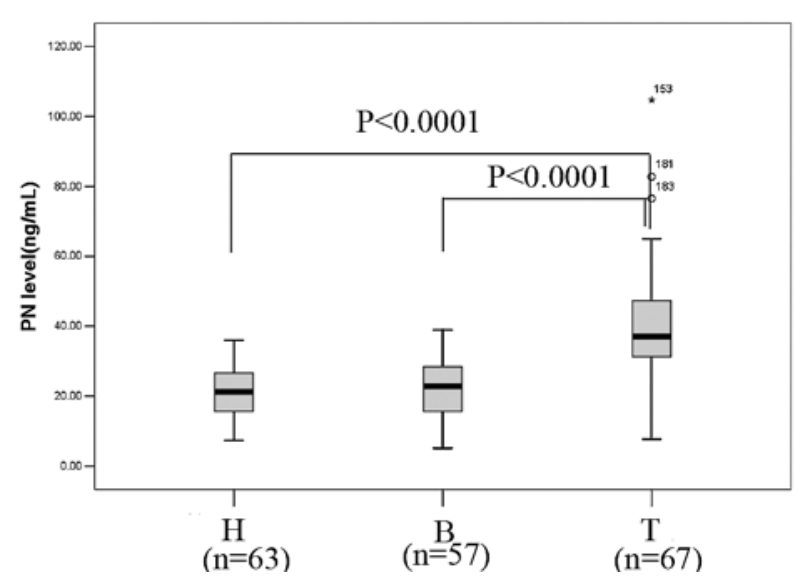

Figure 2. ELISA for human periostin (PN) in serum. (A) Standard curve of human periostin $\left(\mathrm{R}^{2}=0.988\right)$. OD, optical density. (B) Serum periostin levels in patients with CRC $(\mathrm{T})$ compared with healthy volunteers $(\mathrm{H})$ and patients with benign colorectal adenomas or polyps (B). The serum periostin levels were significantly higher than healthy volunteers and colorectal adenomas or polyps $(\mathrm{P}<0.0001)$.

established the standard curve for estimation of the concentration of periostin in sera of the patients (Fig. 2A).

The screening of periostin levels in non-cancer and cancer-patient-derived sera revealed distinct patterns. As shown in Fig. 2B, the serum periostin concentrations in 67 CRC patients $(40.9 \pm 15.4 \mathrm{ng} / \mathrm{ml}$, mean $\pm \mathrm{SD})$ were significantly higher than those in 63 volunteers $(21.0 \pm 7.3 \mathrm{ng} / \mathrm{ml} ; \mathrm{P}<0.0001)$ and in the 57 benign colorectal adenoma or polyp patients $(22.4 \pm 8.5 \mathrm{ng} / \mathrm{ml} ; \mathrm{P}<0.0001)$. We determined the normal range of serum periostin concentration as (6.4-35.6) $\mathrm{ng} / \mathrm{ml}$ (mean in 63 volunteers $\pm 2 \mathrm{SD}$ ). Two subgroups of CRC patients were divided according to the serum levels of periostin as normal $(<35.6 \mathrm{ng} / \mathrm{ml})$ or elevated $(\geq 35.6 \mathrm{ng} / \mathrm{ml})$ at the time of diagnosis.

Concentrations of periostin and clinical features in 67 primary colorectal cancer. As shown in Table II, in the 67 primary CRC patients studied, there was no significant difference in serum periostin levels according to gender $(\mathrm{P}=0.279)$, age $(\mathrm{P}=0.660)$, depth of invasion $(\mathrm{P}=0.193)$, histological grading
Table II. Correlations of serum periostin levels with the clinicopathologic factors in 67 patients with primary colorectal cancer.

\begin{tabular}{lccc}
\hline Characters & $\begin{array}{c}\text { No. of patients } \\
(\%)\end{array}$ & $\begin{array}{c}\text { Serum periostin } \\
\text { levels (ng/ml) }\end{array}$ & P-value \\
\hline $\begin{array}{l}\text { Age, years } \\
<60\end{array}$ & $32(47.8)$ & $40.5 \pm 12.2$ & 0.660 \\
$\geq 60$ & $35(52.2)$ & $39.2 \pm 13.0$ & \\
Gender & & & \\
$\quad$ Male & $42(62.7)$ & $38.5 \pm 12.5$ & 0.279 \\
$\quad$ Female & $25(37.3)$ & $41.4 \pm 12.1$ & \\
Depth of invasion & & & \\
$\quad$ T1-2 & $25(37.3)$ & $37.0 \pm 13.5$ & 0.193 \\
T3-4 & $42(62.7)$ & $41.8 \pm 12.6$ & \\
Node status & & & \\
$\quad$ N0 & $37(55.2)$ & $41.7 \pm 12.8$ & 0.364 \\
N1, N2 & $30(44.8)$ & $38.0 \pm 13.4$ & \\
Metastasis status & & & \\
M0 & $60(89.6)$ & $38.0 \pm 11.4$ & 0.003 \\
M1 & $7(10.4)$ & $56.9 \pm 15.1$ & \\
Tumor differentiation & & & \\
2 & $56(83.6)$ & $39.9 \pm 13.3$ & 0.852 \\
3 & $11(16.4)$ & $40.8 \pm 12.2$ & \\
Site & & & \\
Rectum & $39(58.2)$ & $40.6 \pm 9.8$ & 0.347 \\
Colon & $28(41.8)$ & $38.7 \pm 15.7$ & \\
\hline & & & \\
\hline
\end{tabular}

$(\mathrm{P}=0.852)$, site of lesion $(\mathrm{P}=0.347)$ and node status $(\mathrm{P}=0.364)$ were found. Interestingly, we demonstrated significant difference in serum periostin levels of CRC patients with advanced-stage disease (III/IV) compared with early-stage disease (I/II) $(\mathrm{P}<0.0001$; Fig. 3A). In addition, the serum levels of periostin in CRC patients with metastasis were significantly higher than those with localized lesion $(56.9 \pm 15.1 \mathrm{ng} / \mathrm{ml}$ vs. $38.0 \pm 11.4 \mathrm{ng} / \mathrm{ml}, \mathrm{P}=0.003$; Fig. 3B). Furthermore, based on log-transformed values, we were unable to demonstrate a correlation between periostin concentrations and serum CEA concentrations (correlation coefficient, $0.148 ; \mathrm{P}=0.231 ;$ Fig. $3 \mathrm{C}$ ). This lack of correlation suggested that the two might provide complementary information. Postoperative serum periostin levels in 15 cases were significantly lower than preoperative levels of the same patients $(31.3 \pm 11.0 \mathrm{ng} / \mathrm{ml}$ vs. $47.2 \pm 13.5 \mathrm{ng} / \mathrm{ml}, \mathrm{P}=0.008)$. Two patients showed increased serum periostin levels after operation and 13 patients showed decreased serum periostin levels after operation (Fig. 3D).

Correlation of periostin levels with survival rate. The patients with benign colorectal polyps or adenomas were followed for a median of 16.3 months (range: 12.2-20.5 months) after enrollment, and no one developed CRC. Follow-up also showed that CRC patients with normal levels of periostin have better survival than CRC patients with elevated levels 
A

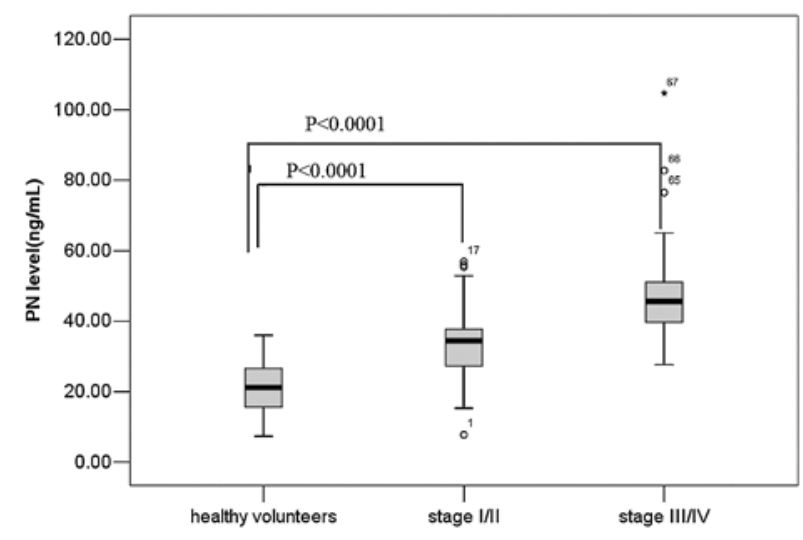

C

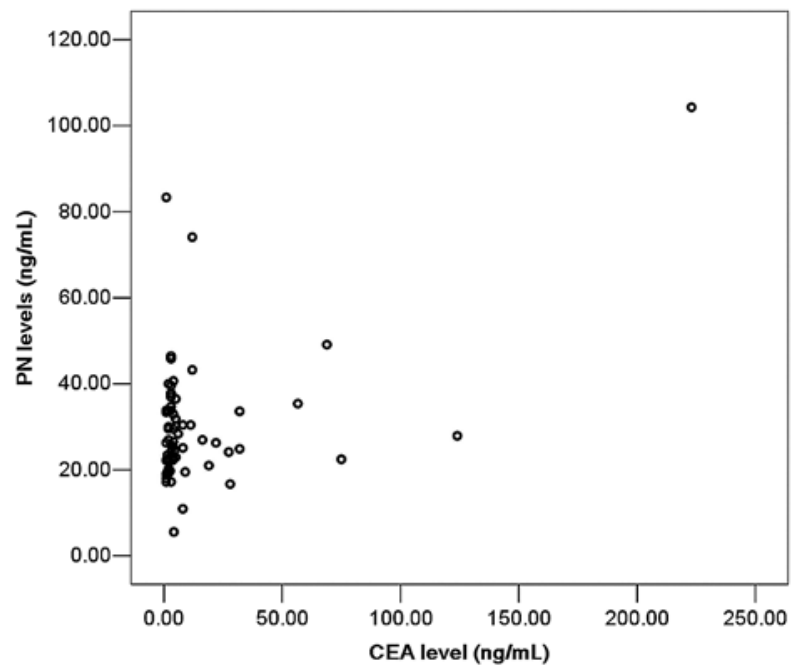

B

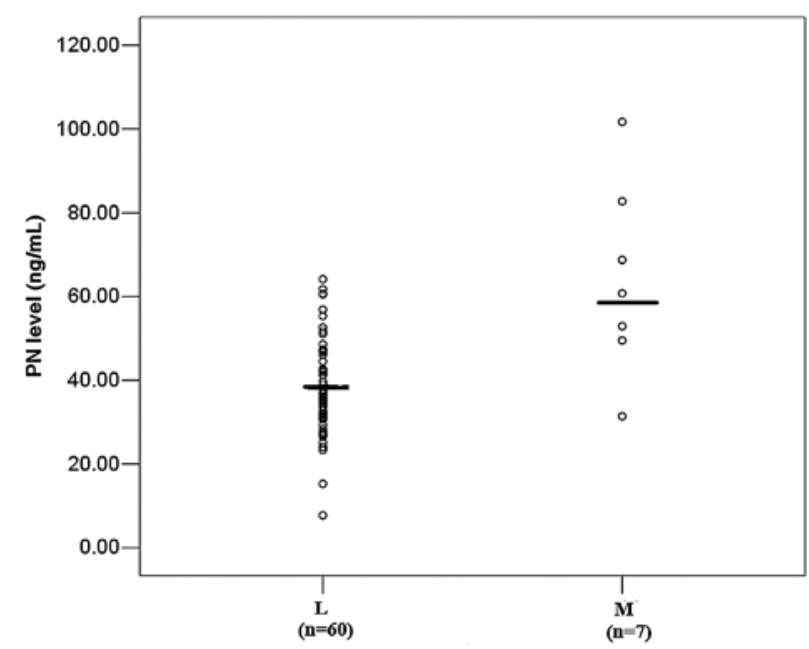

D

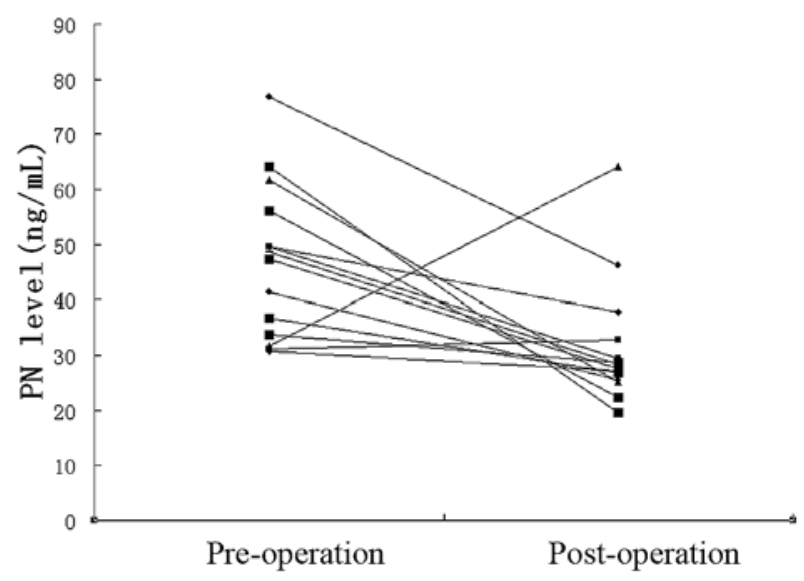

Figure 3. Correlation of serum periostin (PN) levels $(\mathrm{ng} / \mathrm{ml})$ in patients with CRC with clinical features. (A) Serum periostin levels (ng/ml) in patients with CRC at different stages compared with healthy volunteers. (B) Serum periostin levels in patients with CRC with metastasis or not. Means are shown by horizontal bars. (C) Correlations of serum CEA levels and serum periostin levels (correlation coefficient, 0.148; $\mathrm{P}=0.231$ ). (D) The periostin levels after operation revealed a significant decrement below preoperative levels $(\mathrm{P}=0.008)$.

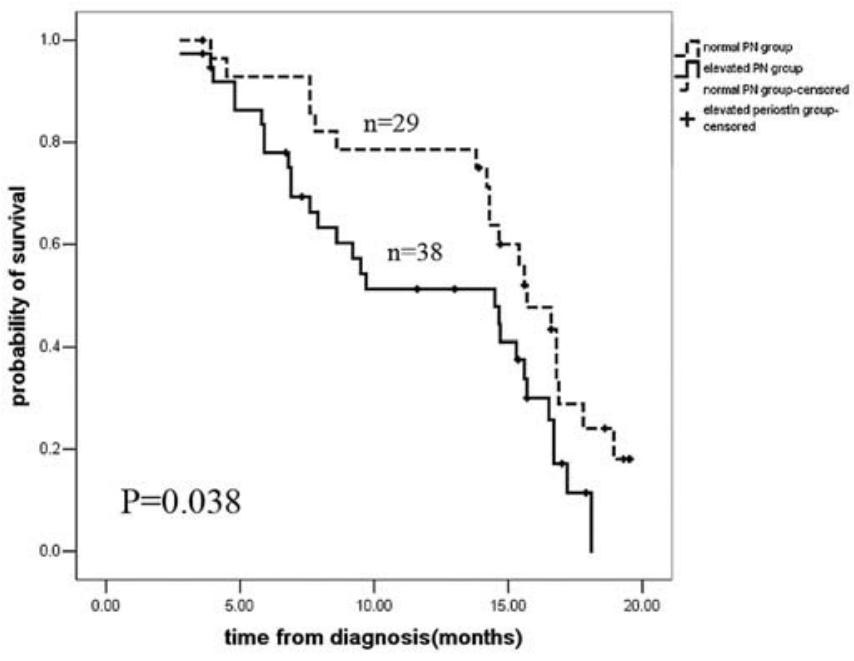

of periostin. The mean survival time of periostin normal group was $14.7 \pm 0.9$ months. The mean survival time of periostin elevated group was $11.7 \pm 0.9$ months. Kaplan-Meier survival curves and log-rank statistics showed that the serum periostin levels can be used as a prognostic biomarker for CRC (Fig. 4, $\mathrm{P}=0.038$ ).

Analysis of periostin expression by immunohistochemistry. To determine localization of periostin protein in human CRC tissue samples, we performed immunohistochemical staining for periostin on two normal colon, two metastatic lymph

Figure 4. Overal survival (OS) analysis (Kaplan-Meier) of the colorectal cancer patients according to the preoperative serum elevated level or normal level of periostin. 

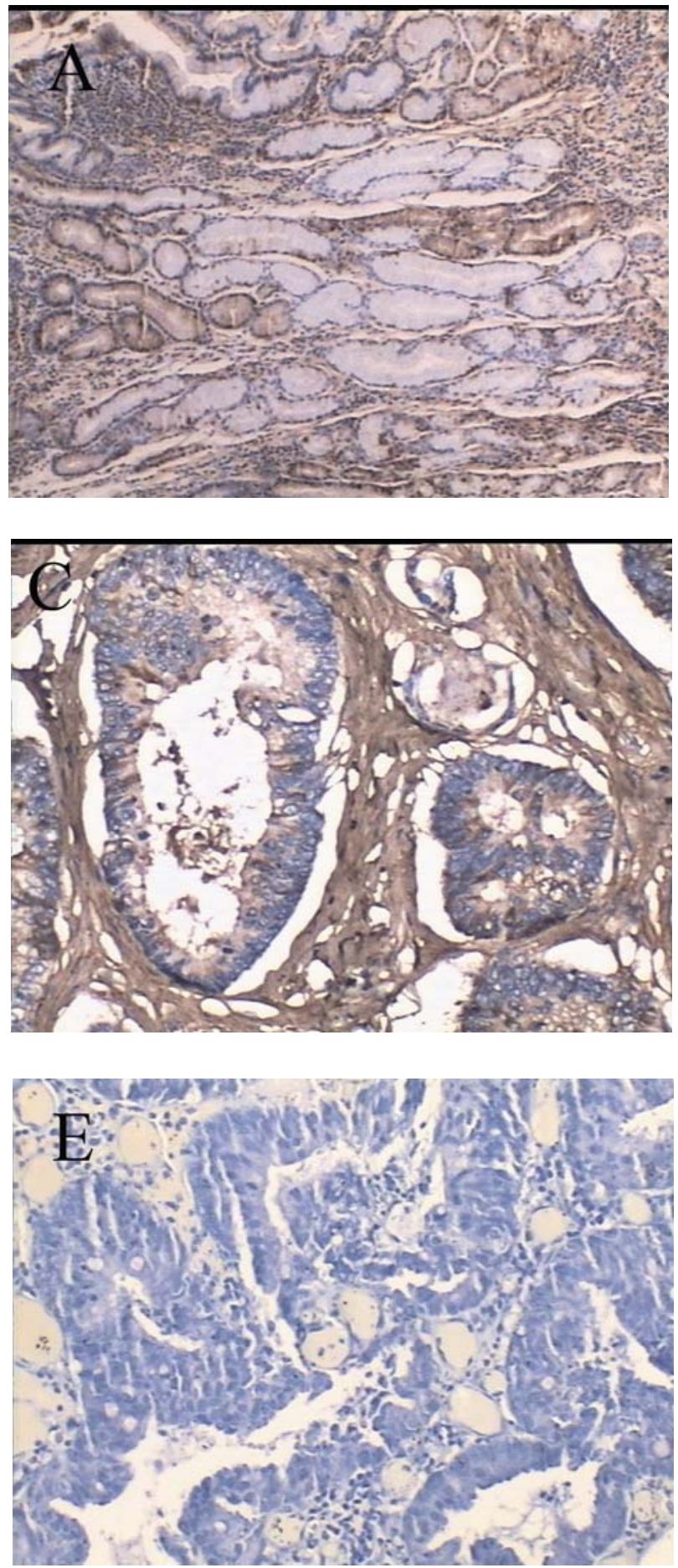

Figure 5. Immunohistochemical analysis of periostin expression in primary and metastatic colorectal cancer tissue samples. The tissue sections were immunostained with a polyclonal antibody. The positive staining for periostin protein is shown in brown color. All sections were counterstained with hematoxylin showing in blue color. (A) Faint staining was seen from normal colorectal tissue section. (B) Periostin were present in stromal areas just surrounding the primary CRC. (C) Metastatic tumors in the lymph node. (D) metastatic tumors in the liver. (E) Negative control. (A: original magnification, x40; B-E: magnification, x200).

nodes, two metastatic liver and 15 cases of primary CRC, including 5 cases of stage II, 9 cases of stage III, and 1 case of stage IV. As shown in Fig. 5, the immunostaining analyses indicated that high levels of periostin were present in stromal
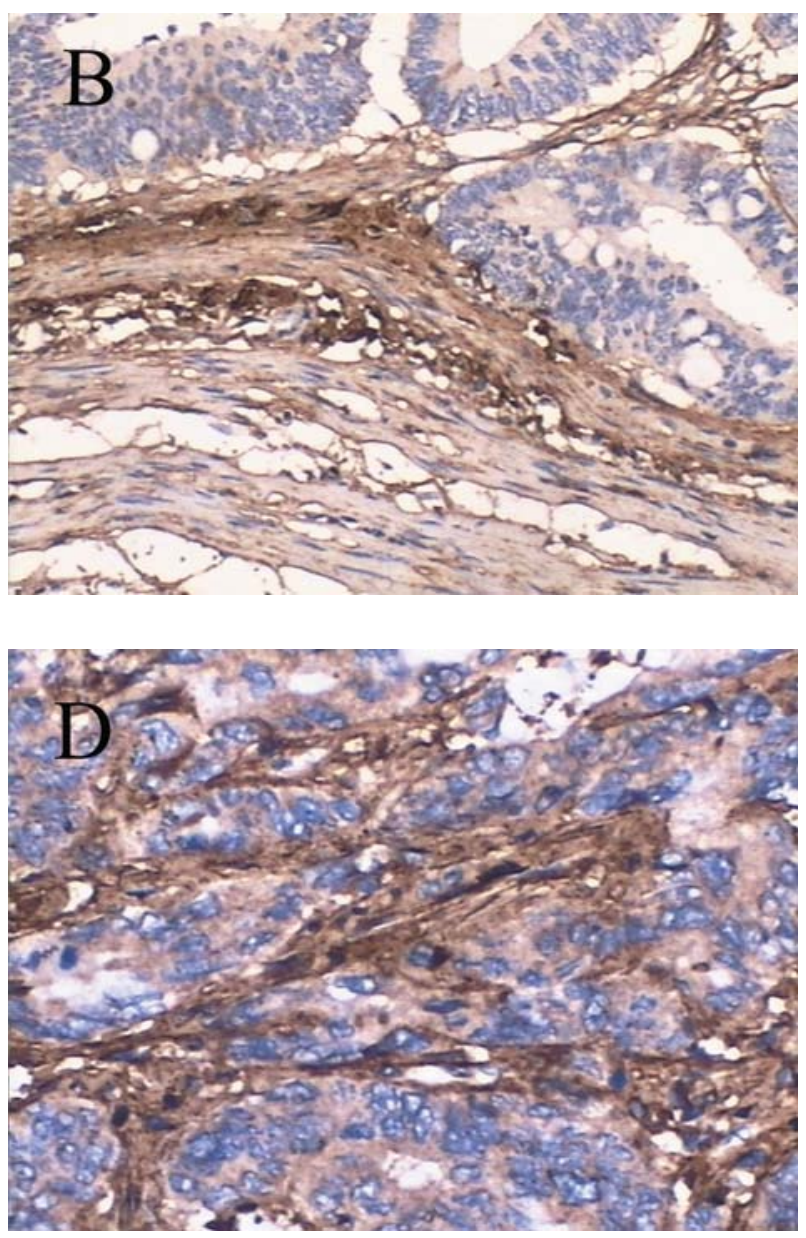

areas just surrounding the primary CRC (Fig. 5B) and metastatic tumors in the liver (Fig. 5C) and in the lymph node (Fig. 5D), whereas very little expression was found in cancer cells themselves. Overall, the majority (80\%) of primary colon tumors displayed prominent levels of periostin staining. No or faint staining was seen from normal colorectal tissue section (Fig. 5A).

\section{Discussion}

The expression of periostin has been shown to play a role in colon cancer progression by influencing cell growth, invasion, and apoptosis $(7,23,24)$. In the present study, we investigated both serum levels and expression of periostin in CRC tissue samples, and analyzed potential correlations between serum periostin levels and certain clinical characteristics of the tumor. We showed that there is up-regulated expression of periostin in the majority of CRC tissue samples and that serum elevated levels of periostin are associated with metastasis, advancedstage disease and dismal outcome of CRC, suggesting that periostin may be related to progression and development of the tumor.

Periostin, an 811-amino acid protein, was originally found to be preferentially expressed in periosteum in bone tissue $(5,6)$. Periostin contains 4 internal repeats sharing a homology with fasciclin I, which leads to the hypothesis that it functions to recruit and attach osteoblasts to the periosteum (25). It has been shown by serial analysis of gene expression (SAGE) 
and multiple genome-wide microarrays that human periostin gene is overexpressed in several human tumors including carcinomas of ovary, breast, pancreas and head and neck squamous cell carcinoma (26-30). On the other hand, acquired expression of periostin by cancer cells greatly promotes metastatic development, adhesion and invasion of cancer cell lines $(7,8,12,13,15)$. Cumulative findings suggest that high expression of periostin might be a common event in tumor development. However, it has also been reported that decreased expression of periostin is associated with progression of bladder cancer in humans $(31,32)$. This confounding results might be due to different functions according to different histopathological types of cancer, or it might be a function of the local periostin concentration in various tissues/experimental settings. One study has demonstrated that periostin has biphasic effects on the migration of pancreatic carcinoma cells (33).

Serum markers for early diagnosis and/or prognostic value of cancer offer several advantages, such as low cost and possibility of detection with rapid and simple tests. Sasaki et al reported (19) that periostin serum level was elevated in breast cancer with bone metastases, and suggested it as a tumor marker in breast cancer. However, it remains unclear what is the correlation between serum levels of periostin and certain clinical characteristics of CRC. In the present study, we demonstrated that preoperative serum concentrations of periostin were significantly higher in CRC patients than in benign colorectal polyps or adenoma and healthy controls, which suggested that the preoperative detection of serum concentrations of periostin might be useful in distinguishing between benign and malignant colorectal diseases, and that periostin might be involved in progression of CRC.

Next, we demonstrated the possible correlation between serum levels of periostin and clinical features in CRC. In fact, serum periostin levels of stage III or IV were significantly higher than that of stage I or II and healthy controls. Furthermore, we demonstrated that serum periostin levels in CRC patients with metastasis were significantly higher than those with localized lesion and that CRC patients with elevated levels of periostin would have worse outcome than patients with normal levels of periostin. All these results suggested that periostin might play a pivotal role in progression and development of the tumor and might serve as a biomarker for monitoring progression, and thus predicting prognosis of CRC.

The source of periostin remains unclear. In the present work, we found that serum periostin levels after surgery revealed a significant decrement below preoperative levels $(\mathrm{P}=0.008)$, which suggested that periostin was produced by the tumor or by other cells responding to the tumor. In this regard, we found that periostin mRNA was not expressed or expressed at low levels in colon cancer cell lines and normal human colorectum tissue samples as compared with CRC tissue samples. In addition, we demonstrated that a high frequency of periostin expression was observed in CRC tissue surrounding primary tumors by immunohistochemistry. All these studies indicated the latter possibility and this was in line with other studies $(12,13,18)$. Erkan et al has identified periostin as an exclusively matrix-specific protein secreted by pancreatic stellate cells in pancreatic carcinoma (18).
It is of note that serum levels of periostin by the current assay are in the $7.7-101.7 \mathrm{ng} / \mathrm{ml}$ range in the controls and CRC patients, whereas previous research based on a chemiluminescence assays by Sasaki et al $(20,21)$ have reported serum levels of periostin $\sim 1,000 \mathrm{ng} / \mathrm{ml}$ in thymoma and NSCLC. These reported values are 2- to 12 -fold higher than the current results. The reason for these discrepancies is unknown, but they may result from the use of different methods and different affinity and avidity of the antibodies.

Collectively the previous and present study suggest that periostin can be a useful marker to predict metastasis and clinical staging in CRC before surgery. The current study also indicates that CRC patients with elevated periostin levels may have a poor prognosis. Prospective studies in a larger population should be carried out to confirm our findings.

\section{Acknowledgements}

We thank Yu Ying Chen, Department of Cell Biology, Basic Medical College, Shanghai Jiaotong University for her excellent technical assistance.

\section{References}

1. Weitz J, Koch M, Debus J, Hohler T, Galle PR and Buchler MW: Colorectal cancer. Lancet 365: 153-165, 2005.

2. Noura S, Yamamoto H, Ohnishi T, et al: Comparative detection of lymph node micrometastases of stage II colorectal cancer by reverse transcriptase polymerase chain reaction and immunohistochemistry. J Clin Oncol 20: 4232-4241, 2002.

3. Thies A, Berlin A, Brunner G, et al: Glycoconjugate profiling of primary melanoma and its sentinel node and distant metastases: implications for diagnosis and pathophysiology of metastases. Cancer Lett 248: 68-80, 2007.

4. Tsukamoto Y, Sakaiuchi T, Hiroi S, et al: Expression of gicerin enhances the invasive and metastatic activities of a mouse mammary carcinoma cell line. Int J Oncol 23: 1671-1677, 2003.

5. Horiuchi K, Amizuka N, Takeshita S, et al: Identification and characterization of a novel protein, periostin, with restricted expression to periosteum and periodontal ligament and increased expression by transforming growth factor beta. J Bone Miner Res 14: 1239-1249, 1999.

6. Takeshita S, Kikuno R, Tezuka K and Amann E: Osteoblastspecific factor 2: cloning of a putative bone adhesion protein with homology with the insect protein fasciclin I. Biochem J 294: 271-278, 1993.

7. Bao S, Ouyang G, Bai X, et al: Periostin potently promotes metastatic growth of colon cancer by augmenting cell survival via the Akt/PKB pathway. Cancer Cell 5: 329-339, 2004.

8. Gillan L, Matei D, Fishman DA, Gerbin CS, Karlan BY and Chang DD: Periostin secreted by epithelial ovarian carcinoma is a ligand for alpha(V)beta(3) and alpha(V)beta(5) integrins and promotes cell motility. Cancer Res 62: 5358-5364, 2002.

9. Baril P, Gangeswaran R, Mahon PC, et al: Periostin promotes invasiveness and resistance of pancreatic cancer cells to hypoxiainduced cell death: role of the beta4 integrin and the PI3k pathway. Oncogene 26: 2082-2094, 2007.

10. Bates RC, Bellovin DI, Brown C, et al: Transcriptional activation of integrin beta6 during the epithelial-mesenchymal transition defines a novel prognostic indicator of aggressive colon carcinoma. J Clin Invest 115: 339-347, 2005.

11. Hashida H, Takabayashi A, Tokuhara T, et al: Integrin alpha3 expression as a prognostic factor in colon cancer: association with MRP-1/CD9 and KAI1/CD82. Int J Cancer 97: 518-525, 2002.

12. Kudo Y, Ogawa I, Kitajima S, et al: Periostin promotes invasion and anchorage-independent growth in the metastatic process of head and neck cancer. Cancer Res 66: 6928-6935, 2006.

13. Siriwardena BS, Kudo Y, Ogawa I, et al: Periostin is frequently overexpressed and enhances invasion and angiogenesis in oral cancer. Br J Cancer 95: 1396-1403, 2006. 
14. Chang Y, Lee TC, Li JC, et al: Differential expression of osteoblast-specific factor 2 and polymeric immunoglobulin receptor genes in nasopharyngeal carcinoma. Head Neck 27: 873-882, 2005.

15. Shao R, Bao S, Bai X, et al: Acquired expression of periostin by human breast cancers promotes tumor angiogenesis through up-regulation of vascular endothelial growth factor receptor 2 expression. Mol Cell Biol 24: 3992-4003, 2004.

16. Fluge O, Bruland O, Akslen LA, Lillehaug JR and Varhaug JE: Gene expression in poorly differentiated papillary thyroid carcinomas. Thyroid 16: 161-175, 2006.

17. Grigoriadis A, Mackay A, Reis-Filho JS, et al: Establishment of the epithelial-specific transcriptome of normal and malignant human breast cells based on MPSS and array expression data. Breast Cancer Res 8: R56, 2006.

18. Erkan M, Kleeff J, Gorbachevski A, et al: Periostin creates a tumor-supportive microenvironment in the pancreas by sustaining fibrogenic stellate cell activity. Gastroenterology 132: 1447-1464, 2007.

19. Sasaki H, Yu CY, Dai M, et al: Elevated serum periostin levels in patients with bone metastases from breast but not lung cancer. Breast Cancer Res Treat 77: 245-252, 2003

20. Sasaki H, Dai M, Auclair D, et al: Serum level of the periostin, a homologue of an insect cell adhesion molecule, in thymoma patients. Cancer Lett 172: 37-42, 2001.

21. Sasaki H, Dai M, Auclair D, et al: Serum level of the periostin, a homologue of an insect cell adhesion molecule, as a prognostic marker in nonsmall cell lung carcinomas. Cancer 92: 843-848, 2001.

22. Sobin LH: TNM, sixth edition: new developments in general concepts and rules. Semin Surg Oncol 21: 19-22, 2003.

23. Kikuchi Y, Kashima TG, Nishiyama T, et al: Periostin is expressed in pericryptal fibroblasts and cancer-associated fibroblasts in the colon. J Histochem Cytochem 56: 753-764, 2008 .
24. Tai IT, Dai M and Chen LB: Periostin induction in tumor cell line explants and inhibition of in vitro cell growth by antiperiostin antibodies. Carcinogenesis 26: 908-915, 2005.

25. Zinn K, McAllister L and Goodman CS: Sequence analysis and neuronal expression of fasciclin I in grasshopper and Drosophila. Cell 53: 577-587, 1988.

26. Friess H, Ding J, Kleeff J, et al: Microarray-based identification of differentially expressed growth- and metastasis-associated genes in pancreatic cancer. Cell Mol Life Sci 60: 1180-1199, 2003.

27. Lal A, Lash AE, Altschul SF, et al: A public database for gene expression in human cancers. Cancer Res 59: 5403-5407, 1999.

28. Chen R, Yi EC, Donohoe S, et al: Pancreatic cancer proteome: the proteins that underlie invasion, metastasis, and immunologic escape. Gastroenterology 129: 1187-1197, 2005.

29. Amatschek S, Koenig U, Auer H, et al: Tissue-wide expression profiling using cDNA subtraction and microarrays to identify tumor-specific genes. Cancer Res 64: 844-856, 2004.

30. Gonzalez HE, Gujrati M, Frederick M, et al: Identification of 9 genes differentially expressed in head and neck squamous cell carcinoma. Arch Otolaryngol Head Neck Surg 129: 754-759, 2003.

31. Kim CJ, Yoshioka N, Tambe Y, Kushima R, Okada Y and Inoue $\mathrm{H}$ : Periostin is down-regulated in high grade human bladder cancers and suppresses in vitro cell invasiveness and in vivo metastasis of cancer cells. Int J Cancer 117: 51-58, 2005.

32. Kim CJ, Isono T, Tambe Y, Chano T, Okabe H, Okada Y and Inoue $\mathrm{H}$ : Role of alternative splicing of periostin in human bladder carcinogenesis. Int J Oncol 32: 161-169, 2008.

33. Kanno A, Satoh K, Masamune A, et al: Periostin, secreted from stromal cells, has biphasic effect on cell migration and correlates with the epithelial to mesenchymal transition of human pancreatic cancer cells. Int J Cancer 122: 2707-2718, 2008. 